\title{
Manche Frauenherzen vertragen keinen Arbeitsstress
}

\section{Termindruck und Arbeitsstress sol- len auch bei Frauen, besonders bei den unter 50-Jährigen, die Herzin- farktrate erhöhen. Das hatten bisher nur Studien bei übergewichtigen männlichen Managern bewiesen.}

— Dänische Wissenschaftler führten eine große Studie zur Inzidenz von ischämischen Herzkrankheiten mit 12116 Krankenschwestern durch. Besonders berücksichtigt wurde der Stress am Arbeitsplatz. Die Frauen waren im Jahr 1993 zu Studienbeginn 45 bis 64 Jahre alt. Zahlreiche Faktoren (Arbeitsstress, -umfeld, Berufscharakteristika, demografische, biologische und Verhaltensrisikofaktoren) wurden gesammelt.

Binnen 15 Jahren wurden 580 Teilnehmerinnen wegen ischämischer Herzkrankheiten hospitalisiert. Der hohe

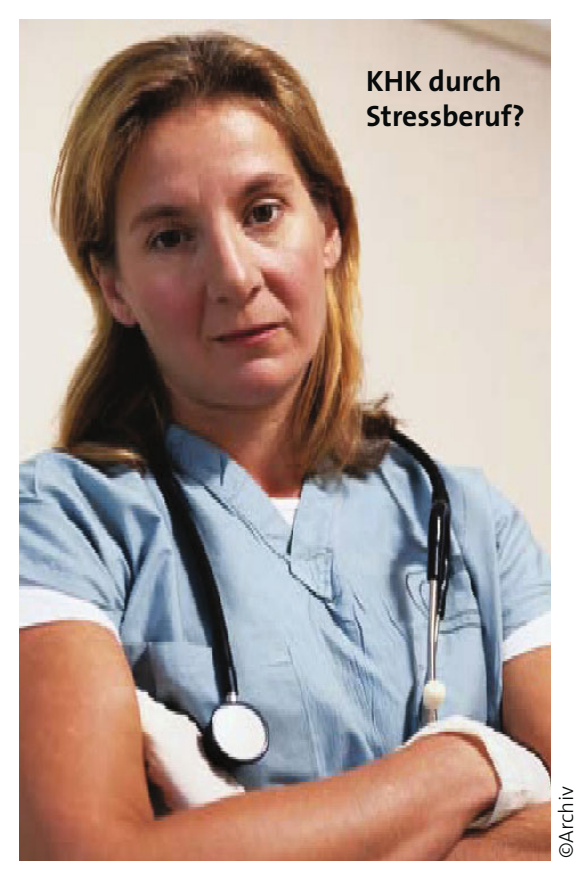

Arbeitsdruck war vor allem für jüngere Frauen $(<51$ Jahren) ein signifikanter Risikofaktor für ischämische Herzkrankheiten.

\section{Kommentar}

Die Ergebnisse sollten bei der Planung der primären Prävention der Herzkrankheiten beachtet werden. Warum ältere Krankenschwestern weniger gefährdet sind, ist nicht sicher zu erklären. Möglicherweise sind besonders stressanfällige Frauen im höheren Lebensalter gar nicht mehr berufstätig.

K. MALBERG =

- K. Allesoem et al.

Psychosocial work environment and risk of ischaemic heart disease in women: the Danish Nurse Cohort Study. Occup. Environ. Med. 67 (2010) 318-322; doi:10.1136/ oem.2008.043091 